\title{
Effects of Electric Pulse Current on the Aging Kinetics of 2219 Aluminum Alloy
}

\author{
Jiao Zhang, ${ }^{1}$ Lihua Zhan, ${ }^{1,2}$ and Shufeng Jia ${ }^{1}$ \\ ${ }^{1}$ State Key Laboratory of High Performance Complex Manufacturing, Central South University, Changsha 410083, China \\ ${ }^{2}$ School of Mechanical and Electrical Engineering, Central South University, Changsha 410083, China \\ Correspondence should be addressed to Lihua Zhan; yjs-cast@csu.edu.cn
}

Received 4 June 2014; Revised 12 August 2014; Accepted 22 August 2014; Published 2 September 2014

Academic Editor: Liyuan Sheng

Copyright (c) 2014 Jiao Zhang et al. This is an open access article distributed under the Creative Commons Attribution License, which permits unrestricted use, distribution, and reproduction in any medium, provided the original work is properly cited.

\begin{abstract}
The conventional aging experiments and the low density electric pulse current (LDEPC for short) added aging experiments, with the self-made positive and negative alternating pulse power equipment, were conducted to study the influence of LDEPC on the dynamics of phase transformation in 2219 aluminum alloy by means of measuring the variation of hardness with aging time. The results showed that the hardness in both aging systems increased with the increasing of aging time until it reached the peak value; then it gradually reduced. The hardness of LDEPC added aging is generally greater than the conventional one before the peak aging time. The Avrami dynamics equation of conventional isothermal aging was obtained based on the hardness evolution law. The effects of electromigration and ponderomotive force were introduced into the Avrami empirical equation; in turn, the dynamics equation of LDEPC added aging was established. At last, the isothermal transformation curves of both the regular aging and the LDEPC added aging were derived which revealed that the nucleation rate, as well as the growth rate, was promoted by electric pulse current. The research work provided the theoretical support for the regulation of the coupling energy field on the dynamics of phase transformation in 2219 aluminum alloy.
\end{abstract}

\section{Introduction}

The electropulsing field, as an effective auxiliary physical field for promoting the forming and improving the property, has been broadly introduced into the casting [1], sintering [2], plastic deformation [3], recrystallization [4], fatigue [5], solid solution [6], and the aging heat treatment process [7]. Currently, higher comprehensive performances for the large structure are needed to meet the requirements of lightweight, safe, and reliable service. Meanwhile the traditional heat treatment system is difficult to further excavate the potential of materials. Therefore, the application of the pulse current field, as an effective auxiliary physical field, in the material heat treatment, has received increasing attention by the scientific research workers. Onodera and Hirano [8] found that the influence of current density on the aging precipitation of aluminum alloy had the threshold that the effects of pulse current would turn inhibition to promotion until it increased to the threshold. Onodera proposed that the directcurrent (D.C) itself retarded the precipitation of the GP zones, and the acceleration of the precipitation resulted from Joule heating. Wang et al. [9] studied the effects of low density D.C current on the precipitation process of $\mathrm{Cu}-\mathrm{Cr}-\mathrm{Zr}$ alloy; the experimental results showed that the low density D.C current greatly promoted the overall precipitation process. Liu et al. [10] discovered that the high density electropulsing aging treatment can both help the copper-nickel alloys achieve the best property rapidly and made the alloy atoms concentrated oriented in the direction of electric pulse current. Liu et al. [11] pointed out that the high density electric pulse treatment can significantly reduce the diffusion activation energy in the process of aging, strengthen the growing rate of $\gamma^{\prime}$ in GH4199 alloy, and change the distribution of multiple precipitations. The research of high density pulse electric current on the GH3044 alloy aging process by Wang [12] revealed that it can lower the aging temperature while improving the nucleation 
TABLE 1: chemical compositions of aluminum alloy 2219 (mass fraction, \%).

\begin{tabular}{lccccccccr}
\hline Ingredient & $\mathrm{Cu}$ & $\mathrm{Mn}$ & $\mathrm{Si}$ & $\mathrm{Fe}$ & $\mathrm{Mg}$ & $\mathrm{Zn}$ & $\mathrm{V}$ & $\mathrm{Zr}$ & $\mathrm{Al}$ \\
\hline Mass fraction & $5.8-6.8$ & $0.2-0.4$ & 0.2 & 0.3 & 0.02 & 0.1 & $0.05-0.15$ & $0.10-0.25$ & $\mathrm{Bal}$ \\
\hline
\end{tabular}

rate of carbides and changing the distribution regularity of precipitate phase in grain boundary. Jia et al. [13] stated that the pulse current would reduce the critical nucleation radius and nucleation work of aging process by studying the effects of pulse current on $\mathrm{Al}_{92.3} \mathrm{Fe}_{4.3} \mathrm{~V}_{0.7} \mathrm{Si}_{1.7} \mathrm{Nd}_{1.0}$ alloy phase transformation kinetics of fast setting process. Conrad [14] attributed the impact of electric current on solid-state phase transition to the effects of electromigration. And To et al. [15] thought that the acceleration of the precipitation was due to the ponderomotive force.

2219 aluminum alloy is a precipitation strengthened high strength alloy which has excellent weld ability, corrosion resistance, and high temperature mechanical properties [16]. It has been widely applied to manufacture the liquid rocket engine fuel tank and other panel structures in the aerospace industry for its high specific strength. The method which introduces the electric pulse current into aging process to improve the microstructure and property of the material has been confirmed by many experiments, but most of them are focused on the qualitative analysis of the influence of high density pulse electric current on the process, microstructure, and performance. The application of low density pulse electric current and its effects on aging kinetics behavior as well as the aging kinetic model considering the effects of electric pulse current has rarely been reported.

In the present work, the positive and negative alternating electrical pulse produced by the self-made low current density electric pulse generator was introduced into the aging treatments of 2219 aluminum alloy samples. The device not only can avoid the obvious joule heating effect caused by the high current density, but also can provide alternating electron flow to make sure the atoms can spread more evenly in the process of aging. The hardness evolution law of 2219 aluminum alloy under different aging systems was clarified, and based on which, the dynamics equation of conventional isothermal aging was obtained. Meanwhile, the effects of electromigration and ponderomotive force were introduced into the Avrami empirical equation to establish the dynamics equation of LDEPC added aging. At last, the isothermal transformation curves of both the conventional aging and the LDEPC added aging were derived.

\section{Experimental Procedure}

2.1. Material. The material used in this experiment was a precipitation strengthened aluminum alloy 2219 with $40 \mathrm{~mm}$ in length, $20 \mathrm{~mm}$ in width, and $2 \mathrm{~mm}$ in thickness; the main chemical components were listed in Table 1.

2.2. Experimental Method. The specimen was quenched into iced water after solution heat treatment at $535^{\circ} \mathrm{C}$ for $35 \mathrm{~min}$ and then divided into two groups, namely, Samples $C$ and Samples EPT. Both of them were then aged at the same

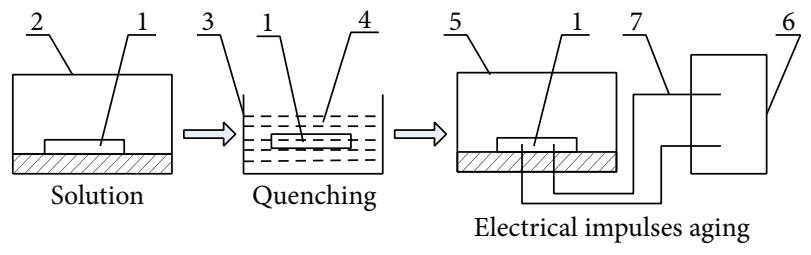

FIGURE 1: Principle of the electrical impulses aging experiment. 1: sample; 2: solution furnace; 3 : the sink; 4: water; 5 : aging furnace; 6 : high precision pulse power device; 7: power supply line.

aging temperature in the same furnace simultaneously, but the Samples EPT were aged under the impact of positive and negative alternating electric current pulse. The schematic view of electric pulse current added aging of the samples is shown in Figure 1.

In this paper, the author adopted the self-made high precision pulse power device of which the pulse peak voltage error is $\pm 0.1 \mathrm{~V}$, as a parameter, maximum current $\left(I_{\max }\right) \approx$ $20 \mathrm{~A}$, duty ratio $(D)=50 \%$, pulse time $(t)=60 \mathrm{~min}$, and frequency $(f)=1000 \mathrm{~Hz}$. A thermocouple was adopted to detect the effect of pulse current on the influence of the temperature rise but there is no change value for instrument; namely, the joule heating effect of pulse current can be ignored. Vickers hardness of the as-aged samples was measured with an HXD$1000 \mathrm{TM}$ tester at a load of $1000 \mathrm{gf}$ after polishing. Each hardness value was calculated from an average of 7 points, after removing the maximum and the minimum.

The TEM analysis of the aged samples was carried out. First, the samples were cut to small pieces with a saw and ground down to about $0.08 \sim 0.1 \mathrm{~mm}$. Then these samples were machined to $3 \mathrm{~mm}$ disks and electropolished, with doublejet equipment operated at a voltage of $15 \mathrm{~V}$, in a solution of $75 \%$ ethanol and $25 \%$ nitric acid solution at about $-25^{\circ} \mathrm{C}$. At last, the TEM microphotographs were obtained from the transmission electron microscopy (FEI Tecnai F20).

\section{Results and Discussion}

3.1. Analysis of the Method to Study Aging Kinetics by Aging Hardness. The aging precipitation process of 2219 aluminum alloy is diffusion controlled solid-state phase transformation, so the isothermal transformation kinetics can be described by the following Avrami equation [17-19]:

$$
f=1-\exp \left(-k t^{n}\right)
$$

where $f$ is the conversion rate, $t$ is the aging time, $n$ is determined by the phase transformation type, and $k$ depends on the nucleation rate and crystal nucleus growth speed 

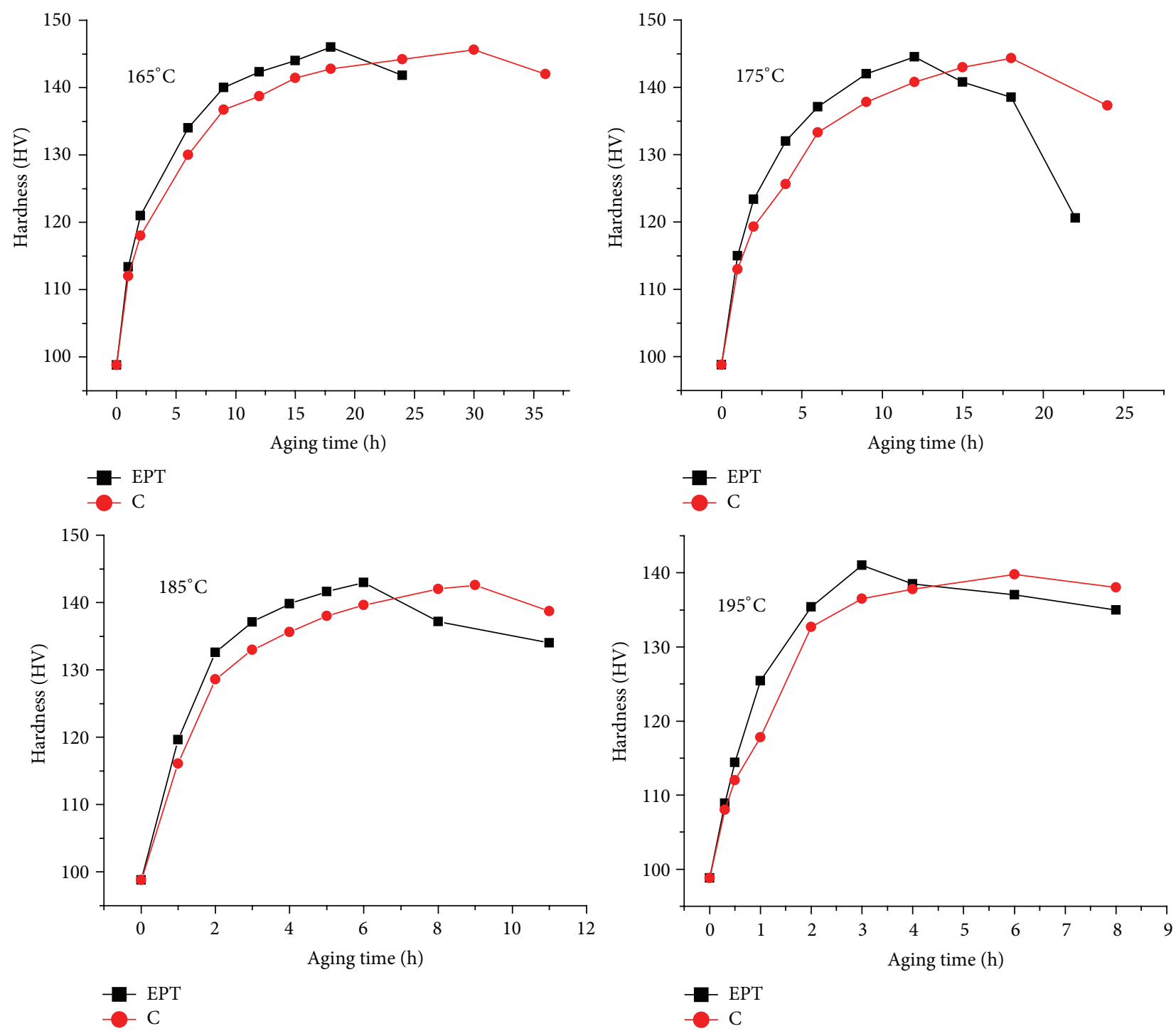

FIgURE 2: Curves of hardening of 2219 aluminum alloy.

determined by temperature, composition, and initial state. The values of $k$ can be expressed as Arrhenius equation:

$$
k=k_{0} \exp \left(-\frac{Q}{R T}\right)
$$

where $k_{0}$ depends on the raw material status, $Q$ is apparent aging activation energy, $R$ is the ideal gas constant $\left(8.31 \mathrm{~J} \cdot \mathrm{mol}^{-1} \cdot \mathrm{K}^{-1}\right)$, and $T$ is the aging temperature. Since the hardness increase before the peak can be attributed to the growing up of precipitates [20], the age hardening curve can approximately represent the conversion of precipitates in the process of ageing. The solid solution point and the peaks of the hardness can be approximately regarded as the starting point and the end point of the transformation, respectively. Meanwhile, every hardness points before the peaks characterize the conversion states. So the conversion rate can be approximately expressed as

$$
f=\frac{\left(H_{t}-H_{0}\right)}{\left(H_{\max }-H_{0}\right)},
$$

where $H_{0}, H_{t}$, and $H_{\max }$ are hardness of the solid solution state $(98.8 \mathrm{HV})$, each moment, and the peak values, respectively.

3.2. Effect of Electric Pulse Current on Aging Process of 2219 Aluminum Alloy. The relationship between the hardness and aging time at different aging temperature is shown in Figure 2. It can be seen that the hardness of both samples increases with increasing of ageing time until it reaches the peak, and then it gradually reduces at any temperature. The hardening rate is enhanced when the aging temperature augments from $165^{\circ} \mathrm{C}$ to $195^{\circ} \mathrm{C}$, but the peak values of the hardness are decreased slightly (as shown in Table 2). 
TABLE 2: Transformation ratio and hardness of the alloy aged at different technologies.

\begin{tabular}{|c|c|c|c|c|c|c|c|c|}
\hline \multirow{2}{*}{$T /{ }^{\circ} \mathrm{C}$} & \multicolumn{4}{|c|}{$\mathrm{EPT}$} & \multicolumn{4}{|c|}{$R$} \\
\hline & $t_{p} / \mathrm{h}$ & $H_{p}(\mathrm{HV})$ & $f=0.1, t / \mathrm{h}$ & $f=0.95, t / \mathrm{h}$ & $t_{p} / \mathrm{h}$ & $H_{p}(\mathrm{HV})$ & $f=0.1, t / h$ & $f=0.95, t / h$ \\
\hline 165 & 18 & 146 & 0.2 & 15.04 & 30 & 145.6 & 0.23 & 20.4 \\
\hline 175 & 12 & 144.5 & 0.18 & 10.95 & 18 & 144.3 & 0.22 & 15.71 \\
\hline 185 & 6 & 143 & 0.17 & 4.22 & 9 & 142.5 & 0.19 & 5.96 \\
\hline 195 & 3 & 141 & 0.12 & 2.87 & 6 & 139.8 & 0.15 & 3.74 \\
\hline
\end{tabular}

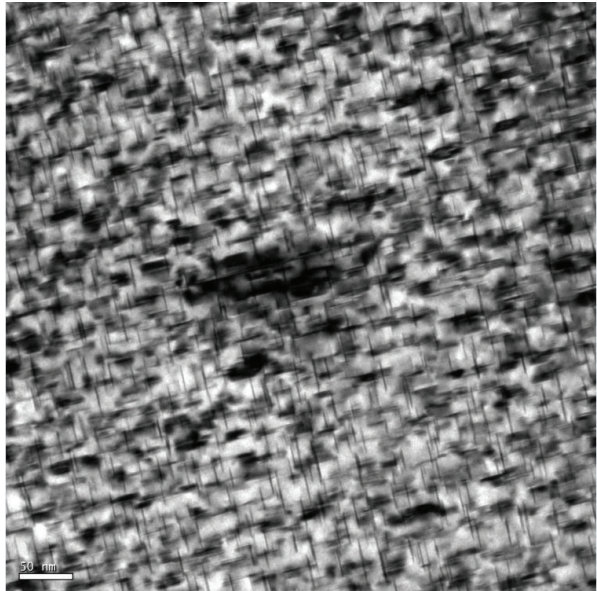

(a)

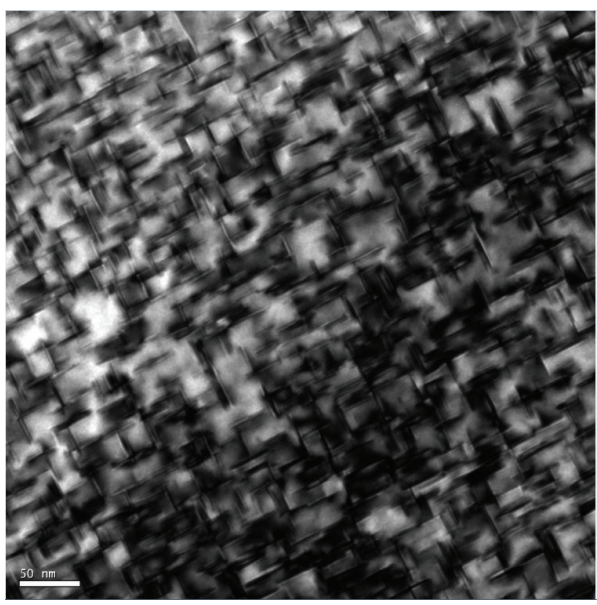

(c)

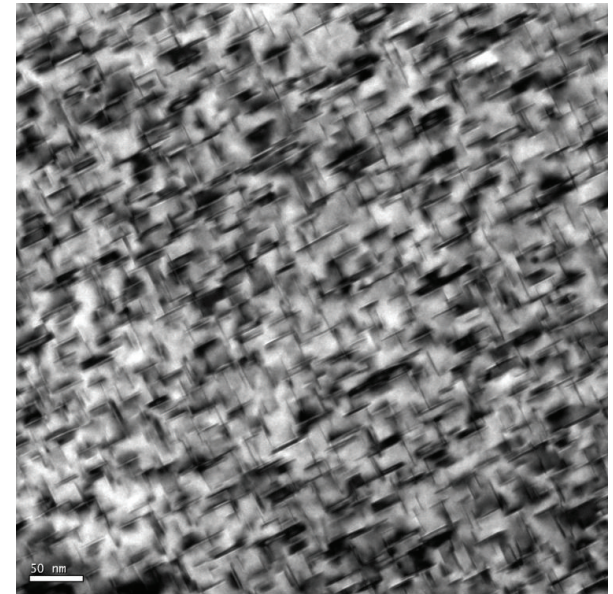

(b)

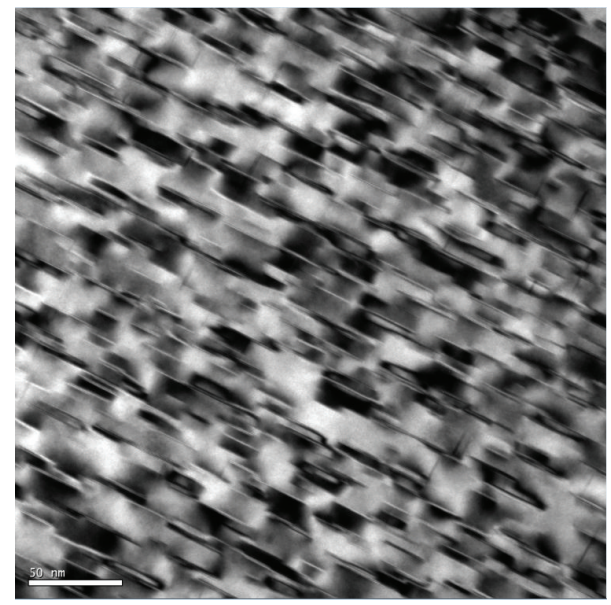

(d)

FIGURE 3: TEM images of 2219 aluminum alloy intracrystalline precipitations aged at $175^{\circ} \mathrm{C}$. (a), (c) conventional aged for $12 \mathrm{~h}, 18 \mathrm{~h}$; (b), (d) LEDPC added aged for $12 \mathrm{~h}, 18 \mathrm{~h}$.

The aging time needed to make sure the hardness reaches the peak value is shortened at any temperature with the introduction of LDEPC; meanwhile, the peak values are increased to some extent. Take $175^{\circ} \mathrm{C}$, for example; the hardness of the alloy aged without current reaches the peak value of HV144.3 at $18 \mathrm{~h}$. While, with the introduction of current, the hardness reaches the peak value of HV144.5 only at $12 \mathrm{~h}$. In general, the hardness of LDEPC added aging is generally greater than the conventional one before the peak aging time. Based on the results above, it can be seen that though raising temperature and imposing LDEPC can both shorten the aging time, the peak hardness of EPT Samples can be improved slightly instead of decreasing.

The build-in strain hardening, shear reinforcement, and by-passing strengthening are three major age hardening mechanisms of aluminum alloy. And incremental reinforcement increases with the size of the precipitation in shear reinforcement mechanism while it does just the opposite in by-passing strengthening mechanism [18].

The TEM microphotographs in Figure 3 show the distribution of intracrystalline precipitates when the specimens were aged at $175^{\circ} \mathrm{C}$ for $12 \mathrm{~h}, 18 \mathrm{~h}$ with and without LEDPC, 


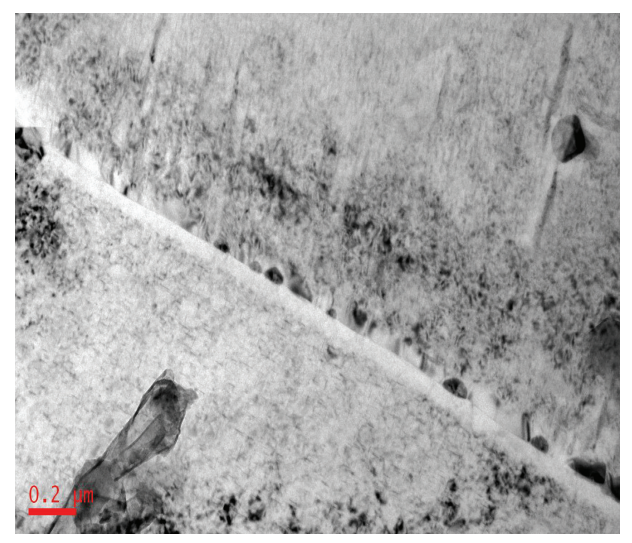

(a)

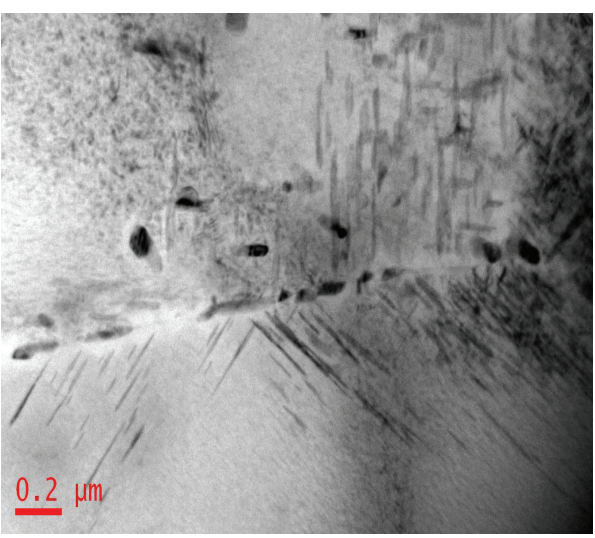

(b)

FIGURE 4: TEM images of 2219 aluminum alloy grain boundary precipitations in the peak aging state aged at $175^{\circ} \mathrm{C}$. (a) Conventional aged for $18 \mathrm{~h}$; (b) LEDPC added aged for $12 \mathrm{~h}$.

TABLE 3: The parameters and the equations of aging kinetics at different temperature.

\begin{tabular}{lcccc}
\hline$T /{ }^{\circ} \mathrm{C}$ & $k / \mathrm{h}^{-1}$ & $n$ & $f / \%$ & $\mathrm{Q} / \mathrm{KJmol}^{-1}$ \\
\hline 165 & 0.32 & 0.74 & $f=1-\exp \left(-0.32 t^{0.74}\right)$ & \\
175 & 0.34 & 0.79 & $f=1-\exp \left(-0.34 t^{0.79}\right)$ & 52.0 \\
185 & 0.53 & 0.97 & $f=1-\exp \left(-0.53 t^{0.97}\right)$ & $4.6 \times 10^{5}$ \\
195 & 0.75 & 1.05 & $f=1-\exp \left(-0.75 t^{1.05}\right)$ & \\
\hline
\end{tabular}

respectively. A large number of vertical distributions of small plate sheet (projection for long and thin needle) precipitation $\theta^{\prime}\left(\mathrm{Al}_{2} \mathrm{Cu}\right)$ [21] can be found in the matrix of 2219 aluminum alloy aged conventionally at $175^{\circ} \mathrm{C}$ for $12 \mathrm{~h}$ (as shown in Figure 3(a)) and the shear reinforcement mechanism in which the incremental reinforcement increases with the size of the precipitations is the main influence mechanism in the case. So with the aging time extended to $18 \mathrm{~h}$, the value of hardness increased to the peak for the growth of precipitations where apparent coarsening has not appeared yet (as shown in Figure 3(c)).

While the value of hardness, in the case of LEDPC added aging, reached the peak only for $12 \mathrm{~h}$ and the distribution of precipitations was more even and dispersive than the conventional one in the peak aging state (as shown in Figure 3(b)), the comparison between Figures 3(a) and 3(b) which were both aged at $175^{\circ} \mathrm{C}$ for $12 \mathrm{~h}$ demonstrated that the growing speed of precipitation $\theta^{\prime}\left(\mathrm{Al}_{2} \mathrm{Cu}\right)$ was promoted by LEDPC. Meanwhile it can be seen from the comparison between Figures 3(b) and 3(c) of which the value of hardness reached the peak that the nucleation rate was also promoted by LEDPC [22] for the distribution of precipitations was more even and dispersive than the conventional one. With the aging time extended to $18 \mathrm{~h}$, the hardness decreased for apparent coarsening of precipitation where by-passing strengthening mechanism played dominant role. Meanwhile the hardness of sample decreased again for the anisotropic distribution of precipitations (as shown in Figure 3(d)).

The distribution of grain boundary precipitations, in the peak aging state aged at 175 with and without LEDPC, respectively, was shown in Figure 4 . It can be seen that both of the grain boundary precipitations were distributed discretely, but the width of grain boundary precipitation free zones was decreased by LEDPC distinctly which contributed to the augmentation of hardness in the peak aging state.

3.3. Effect of Electric Pulse Current on Aging Kinetics of 2219 Aluminum Alloy. In order to study the effects of pulse current on 2219 aluminum alloy aging kinetics, it is necessary to obtain the aging dynamics equation of 2219 aluminum alloy in conventional aging system by acquiring the parameters of Avrami empirical equation based on the hardening curves. Then the kinetics model of LDEPC added aging process was built by introducing the mechanism of pulse current. Further, the isothermal transformation curve of both the regular aging and the LDEPC added aging can be derived to reflect the effects of pulse current intuitively.

\subsubsection{Fitting of Regular Aging Kinetics Curves and Parameter} Determination. Since the aging precipitation kinetics equation can be characterized by the preliminary aging hardening curve, the relationship between the conversion rate and the aging time at any temperature can be obtained by type (3). Based on all of the hardness after the conventional underaged treatment at any temperature, the conventional aging kinetics models (as shown in Table 3) are found by means of nonlinear fitting (as shown in Figure 5). Then the values of $Q$ and $k_{0}$ (as shown in Table 3 ) are obtained by plotting $\ln k$ versus $1 /(R \cdot T)$ (as shown in Figure 6).

It can be seen from Figure 5 that the Avrami empirical equation can describe the phase transition process of 2219 


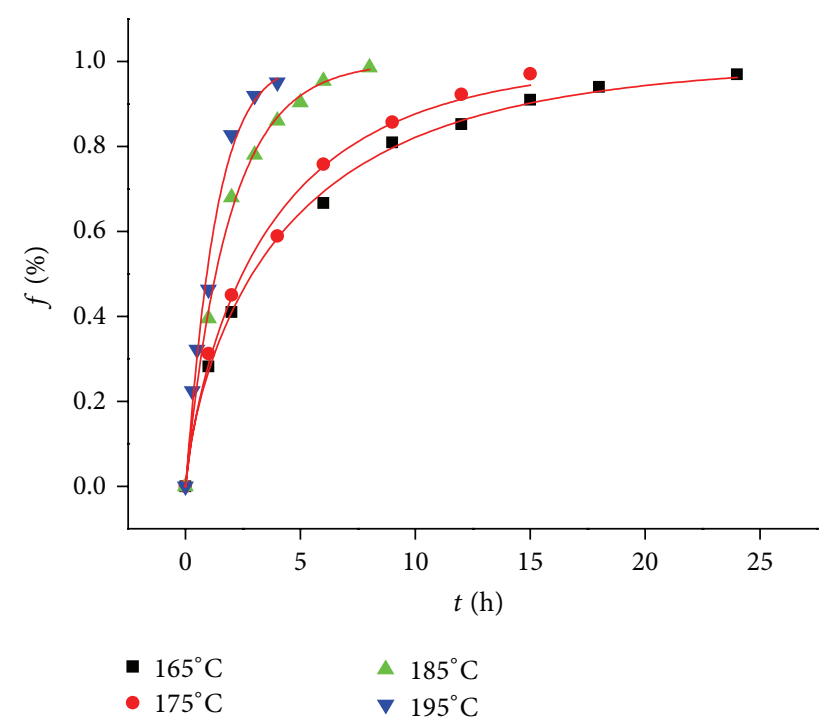

FIGURE 5: Fitting of regular aging kinetics curves.

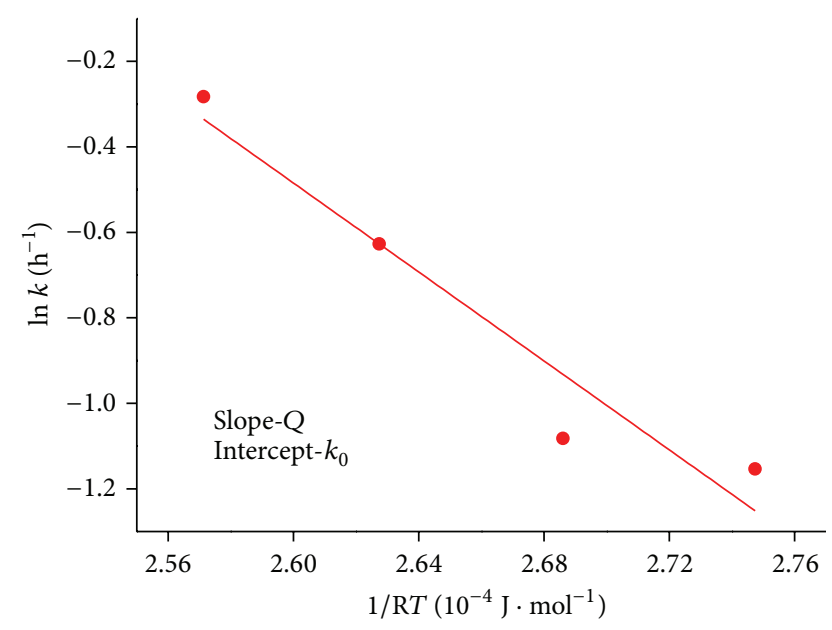

FIGURE 6: Relationship between $\ln k$ and $1 /(R \cdot T)$ of samples $R$.

aluminum alloy very well and the phase transformation rate increases with increasing of temperature.

3.3.2. LDEPC Added Aging Kinetic Model. It is necessary for the conventional aging kinetic model to be further revised after introducing the pulse current for it only considered the effects of temperature and the original state of material. The existing research shows that the electromigration and the ponderomotive force caused by pulse current which can be expressed by $\Delta \Phi=2 N \cdot D \cdot Z^{*} \cdot e \cdot \rho \cdot f \cdot j_{m} \cdot \tau_{p} /(\pi \cdot k \cdot T)$ and $\Delta W e=\mu_{0} \cdot g \cdot \varepsilon\left(\sigma_{1}, \sigma_{2}\right) j^{2} \Delta V$, respectively, [14, 23-25] are the main factors to affect the atom diffusion and the free energy difference, respectively, which further affect the precipitation process (since the temperature rise caused by pulse current is small, the joule heating effect can be ignored). Since the aging precipitation process of 2219 aluminum alloy is diffusion controlled solid-state phase transformation, on the one hand additional atomic flux will produce an increment
TABLE 4: Correction coefficient.

\begin{tabular}{lcc}
\hline$T /{ }^{\circ} \mathrm{C}$ & $\lambda$ & $q$ \\
\hline 165 & 3.60238 & 0.08629 \\
175 & 2.4846 & 0.08043 \\
185 & 3.29345 & 0.08794 \\
195 & 3.15639 & 0.08314 \\
\hline average & 3.134205 & 0.08445 \\
\hline
\end{tabular}

of $k$ by affecting the aging process directly, and on the other hand the electromigration will affect the activation energy $Q$ by influencing the difference of free energy. The effects of electromigration and ponderomotive force difference were simplified to coefficients of $\lambda$ and $q$, respectively, and both of them will become zero for the process of conventional aging in accordance with the normal aging kinetic model. Therefore, the revised aging dynamics model is expressed as

$$
k=(1+\lambda) k_{0} \exp \left(-\frac{(1+q) Q}{R T}\right)
$$

where $\lambda$ characterizes the effects of the electromigration on atomic drift flux, $q$ characterizes the effects of the ponderomotive force on the free energy difference, and $n$ remains unchanged in this model for it was decided by the type of phase transformation. Based on all of the hardness after the electropulsing under-aged treatment at any temperature, the values of $\lambda$ and $q$ are obtained (as shown in Table 4 ) by means of nonlinear fitting (as shown in Figure 7). The validation of the revised model is shown in Figure 8.

It can be seen from Table 4 and Type (4) that the electromigration caused by pulse current significantly promoted the aging precipitation process by increasing the nucleation rate and crystal nucleus growing speed, while the introduction of the ponderomotive force slightly inhabited the aging precipitation by increasing the aging activation energy. But combination of them still significantly contributed to the phase transformation process. The revised model is shown in Figure 5; it is clear that the revised model can greatly describe the phase transition process of 2219 aluminum alloy under the effects of pulse current.

3.3.3. The Isothermal Transformation Curve. Take $f=10 \%$, $95 \%$ as the start and the end point of transformation, respectively; then the isothermal transformation curve (as shown in Figure 9) in both aging systems can be obtained by acquiring the start/end time (as shown in Table 2).

It can be seen from Figure 9 that the transition time is shortened with increasing of temperature from $165^{\circ} \mathrm{C}$ to $195^{\circ} \mathrm{C}$, which reveals that the precipitation process at $165 \sim$ $195^{\circ} \mathrm{C}$ is a kinetically limited process which is consistent with Papazian's research [26]. Meanwhile both the induction period and the whole period of transformation are shortened with the imposition of pulse current, for all of the isothermal transformation curves are shifted to the left. It can be also indicated that the pulse current not only increased the nucleation rate but also promoted the growing up of crystal 


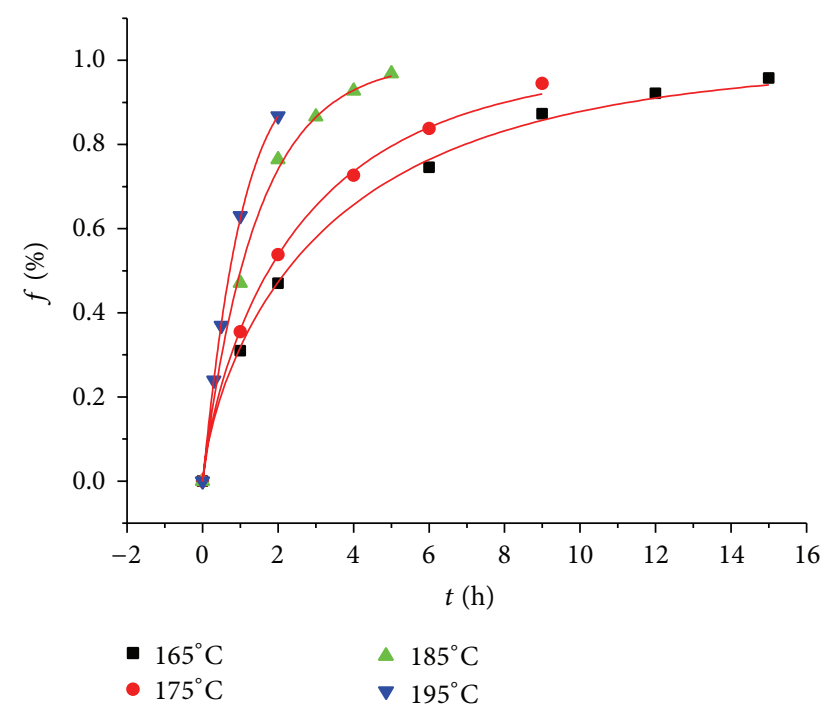

FIGURE 7: Fitting of electric pulses aging kinetics curves.

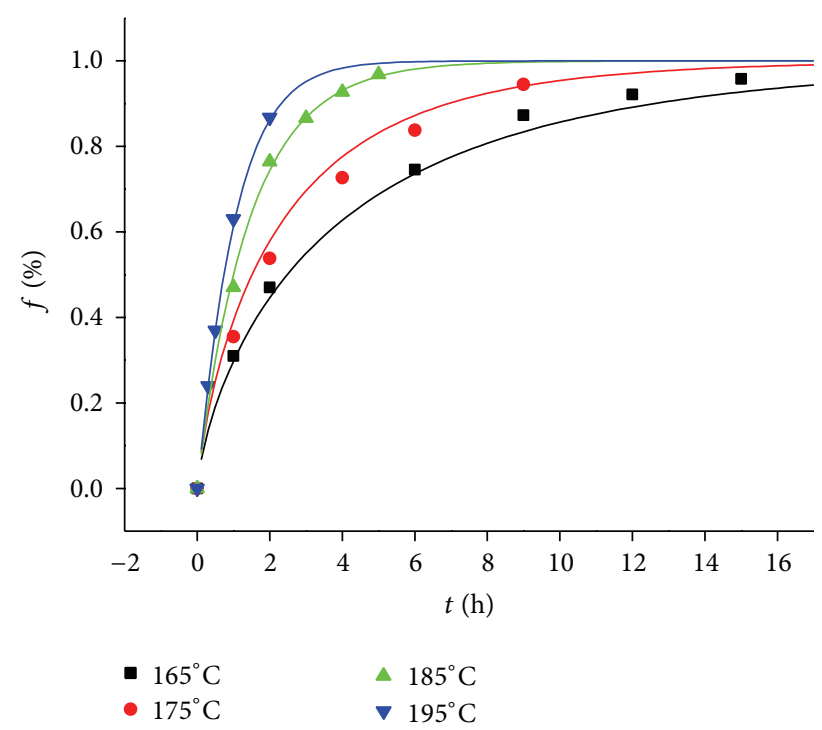

FIGURE 8: Validation of the revised model.

nucleus for the difference of the end curves is about 2.2 times of the starting curves.

\section{Conclusions}

(1) The LDEPC significantly promoted the aging process of 2219 aluminum alloy by shortening the aging time and increasing the peak values of hardness.

(2) Avrami empirical equation can describe the conventional aging kinetics of 2219 aluminum alloy very well with $Q=52.0 \mathrm{KJmol}^{-1}, k_{0}=4.6 \times 10^{5} \mathrm{~h}^{-1}$, and the value of $n$ increases with increasing of temperature.

(3) The electromigration significantly promoted the aging precipitation process while the introduction of

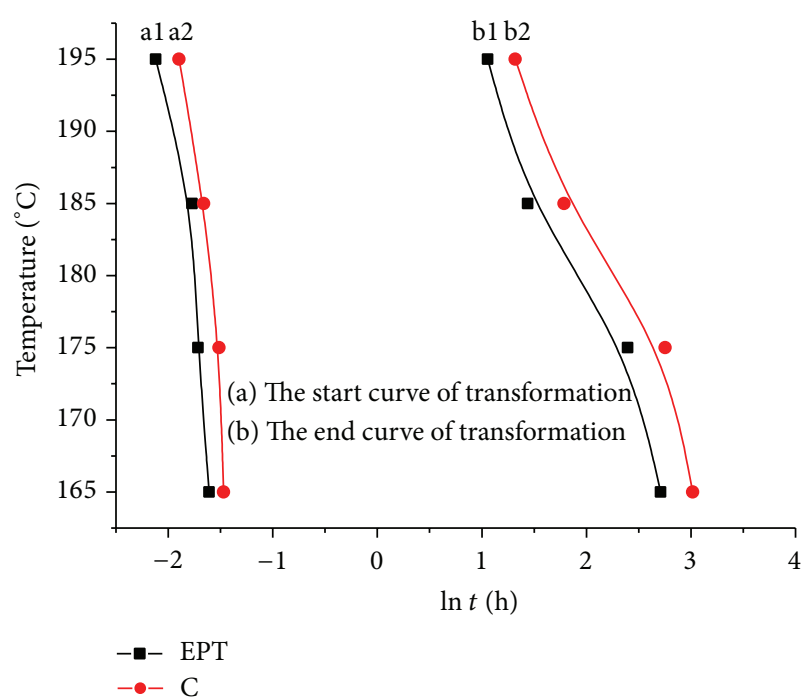

FIGURE 9: The isothermal transformation curve.

the ponderomotive force slightly inhabited the aging precipitation.

(4) The precipitation process at $165 \sim 195^{\circ} \mathrm{C}$ is a kinetically limited process; the pulse current not only shortened the induction period of transformation but also shortened the whole transformation time in the end.

(5) Both the nucleation rate and the growing speed were increased by pulse current, and the research work provided the theoretical support for the regulation of the coupling energy field on the dynamics of phase transformation in 2219 aluminum alloy.

\section{Conflict of Interests}

The authors declare that there is no conflict of interests regarding the publication of this paper.

\section{Acknowledgments}

This research was supported by the Key Program of National Natural Science Foundation of China (Grant no. 51235010), the Major State Basic Research Program of China (973 Program) (Grant no. 2014CB046602), and Ph.D. Programs Foundation of Ministry of Education of China (Grant no. 20120162110003).

\section{References}

[1] W. J. Chen, X. L. Liao, C. H. Gan, Y. Fang, and Q. J. Zhai, “Effects of pulse electric current on directional solidification structure of Al-4.5Cu alloy," Special Casting and Nonferrous Alloys, vol. 26, no. 8, pp. 523-525, 2006.

[2] M. Suganuma, Y. Kitagawa, S. Wada, and N. Murayama, "Pulsed electric current sintering of silicon nitride," Journal of the American Ceramic Society, vol. 83, no. 3, pp. 387-394, 2003. 
[3] L. Guan, G. Tang, and P. K. Chu, "Recent advances and challenges in electroplastic manufacturing processing of metals," Journal of Materials Research, vol. 25, no. 7, pp. 1215-1224, 2010.

[4] Z. S. Xu, Z. H. Lai, and Y. X. Chen, "Effect of electric current on the recrystallization behavior of cold worked $\alpha$ - Ti," Scripta Metallurgica, vol. 22, no. 2, pp. 187-190, 1988.

[5] J.-Y. Zheng, W. He, and Y.-B. Shi, "Eliminating residual stress in 45 steel quenching specimens by electrical pulse," Journal of Zhejiang University, vol. 46, no. 8, pp. 1407-1411, 2012.

[6] L. J. He, J. G. Qi, J. Z. Wang, L. Y. Cao, and D. Q. Cang, "Effeets of current pulse during solution proeess on microstructure of Al-22\% Si-1.5\% Cu alloy," Transactions of Materials and Heat Treatment, vol. 28, supplement 1, pp. 38-40, 45, 2007.

[7] G. Li, L. Wang, Y. Liu, W. Zhang, X. Qiao, and Y. Wang, "Effects of high density electropulsing treatment on aging kinetics of GH4199 alloy," Rare Metal Materials and Engineering, vol. 40, no. 6, pp. 961-966, 2011.

[8] Y. Onodera and K.-I. Hirano, "The effect of direct electric current on precipitation in a bulk Al-4 wt \% Cu alloy," Journal of Materials Science, vol. 11, no. 5, pp. 809-816, 1976.

[9] Z. Wang, Y. Zhong, G. Cao et al., "Influence of dc electric current on the hardness of thermally aged $\mathrm{Cu}-\mathrm{Cr}-\mathrm{Zr}$ alloy," Journal of Alloys and Compounds, vol. 479, no. 1-2, pp. 303-306, 2009.

[10] S. Q. Liu, J. L. Huang, P. Liu, and Q. M. Dong, "Effect of electtric pulse current on microstructure and properties of $\mathrm{Cu}-\mathrm{Ni}-\mathrm{Si}$ alloy," Journal of Henan University of Science and Technology (Natural Science), vol. 24, no. 3, pp. 4-10, 2003.

[11] Y. Liu, L. Wang, F. Feng, B. J. Zhang, and G. P. Zhao, "Effects of electropulsing treatment on coarsening behavior of $\gamma$ ' phase in a nickel base superalloy," Journal of Materials and Metallurgy, vol. 10, no. 4, pp. 288-291, 2011.

[12] Y. C. Wang, Effects of pulse current treatment on the precipitation behavior of carbides for GH3044 [Ph.D. thesis], Northeastern University, Shenyang, China, 2009.

[13] W. Jia, J.-N. Deng, and M.-G. Zeng, "Effect of electropulsing on the phase transformation dynamics of Al-matrix nanocrystalline alloy," Transactions of Materials and Heat Treatment, vol. 25, no. 1, pp. 5-7, 2004.

[14] H. Conrad, "Effects of electric current on solid state phase transformations in metals," Materials Science and Engineering A, vol. 287, no. 2, pp. 227-237, 2000.

[15] S. To, Y. H. Zhu, W. B. Lee, G. Y. Tang, X. M. Liu, and Y. B. Jiang, "Effects of dynamic electropulsing on phase transformation of a zn-al based alloy," Materials Transactions, vol. 50, no. 5, pp. 1105-1112, 2009.

[16] Y. Liu, X.-M. Zhang, H.-Z. Li, B. Liu, H. Gao, and H.-J. Li, "Tensile properties of three kinds of aluminum alloys at low temperature," Heat Treatment of Metals, vol. 32, no. 1, pp. 5356, 2007.

[17] Z. Q. Zhen, Fundamentals of Material Science, Science Press, Beijing, China, 1st edition, 2006.

[18] Y. P. Kang, Metal Solid State Phase Transition and Application, Chemical Industry Press, Beijing, China, 1st edition, 2007.

[19] Y. Li and D.-Q. Yi, "Dynamics of phase transformation in $\mathrm{Cu}-$ Fe-Ag alloy," Transactions of the Metal Heat Treatment, vol. 31, no. 5, pp. 49-52, 2010.

[20] X. J. Jiang, D. P. Yao, and Y. Y. Li, "Precipitation kinetics in AlLi-Zn-Zr alloys," Materials For Mechanical Engineering, no. 76, pp. 27-29, 1990.
[21] Z.-Y. Liu, Y.-T. Li, Y.-B. Liu, and Q.-K. Xia, "Development of Al-Cu-Mg-Ag alloys," The Chinese Journal of Nonferrous Metals, vol. 17, no. 12, pp. 1905-1915, 2007.

[22] Y. Z. Zhou, J. D. Guo, W. Z. Zhang, and G. H. He, "Influence of electropulsing on nucleation during phase transformation," Journal of Materials Research, vol. 17, no. 12, pp. 3012-3014, 2002.

[23] Y. B. Jiang, G. Y. Tang, L. Guan et al., "Effect of electropulsing treatment on solid solution behavior of an aged Mg alloy AZ61 strip," Journal of Materials Research, vol. 23, no. 10, pp. 26852691, 2008.

[24] S. To, Y. H. Zhu, W. B. Lee, X. M. Liu, and Y. B. Jiang, "Effects of current density on elongation of an electropulsing treated $\mathrm{Zn}$ Al based alloy," Materials Transactions, vol. 50, no. 12, pp. 27722777, 2009.

[25] J. H. Fan, "Fundamental research on refinement of solidification structure of metals with pulse current," Journal of Shanghai University, vol. 10, no. 5, pp. 471-472, 2006.

[26] J. M. Papazian, "Calorimetric studies of precipitation and dissolution kinetics in aluminum alloys 2219 and 7075," Metallurgical Transactions A, vol. 13, no. 5, pp. 761-769, 1982. 

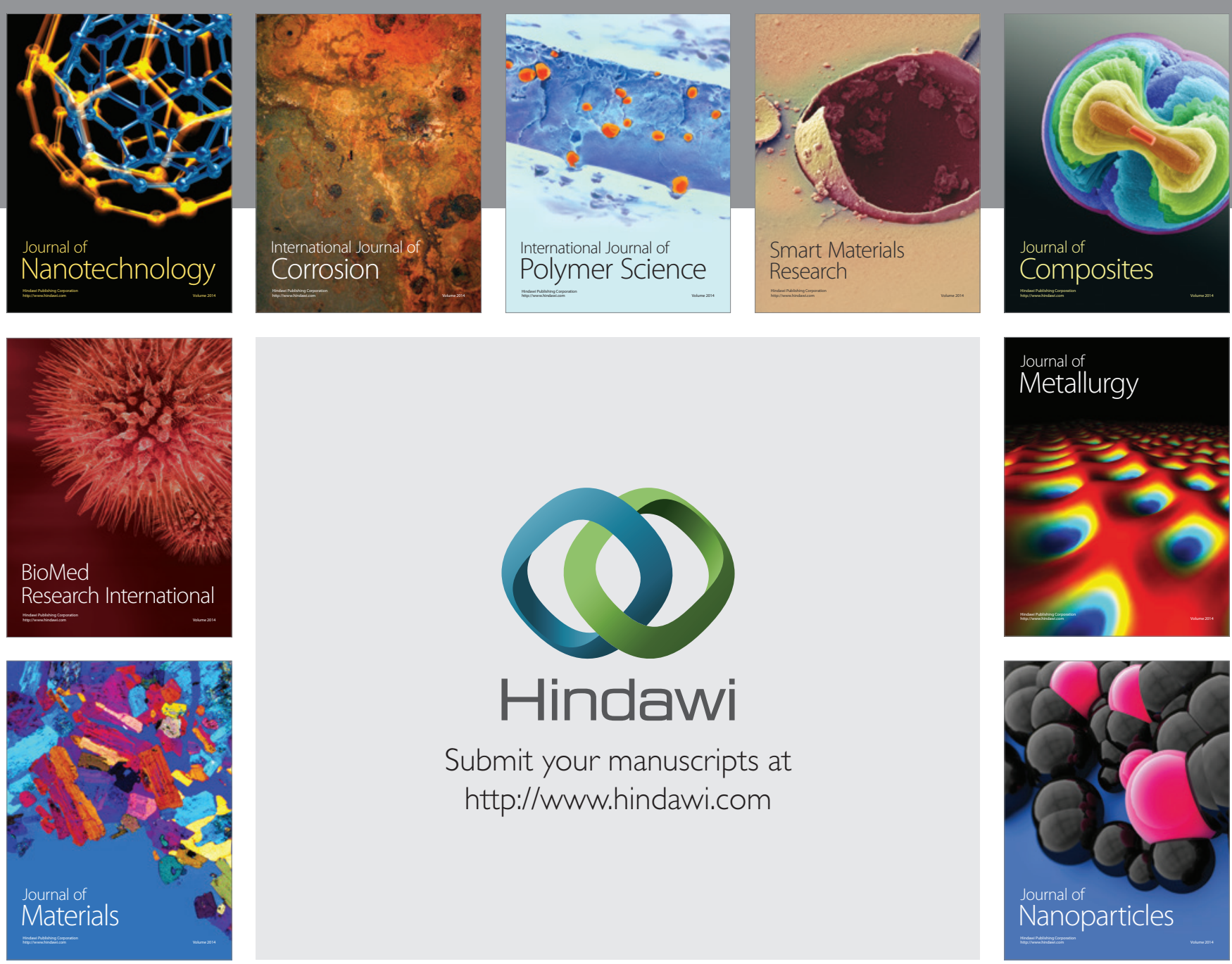

Submit your manuscripts at http://www.hindawi.com
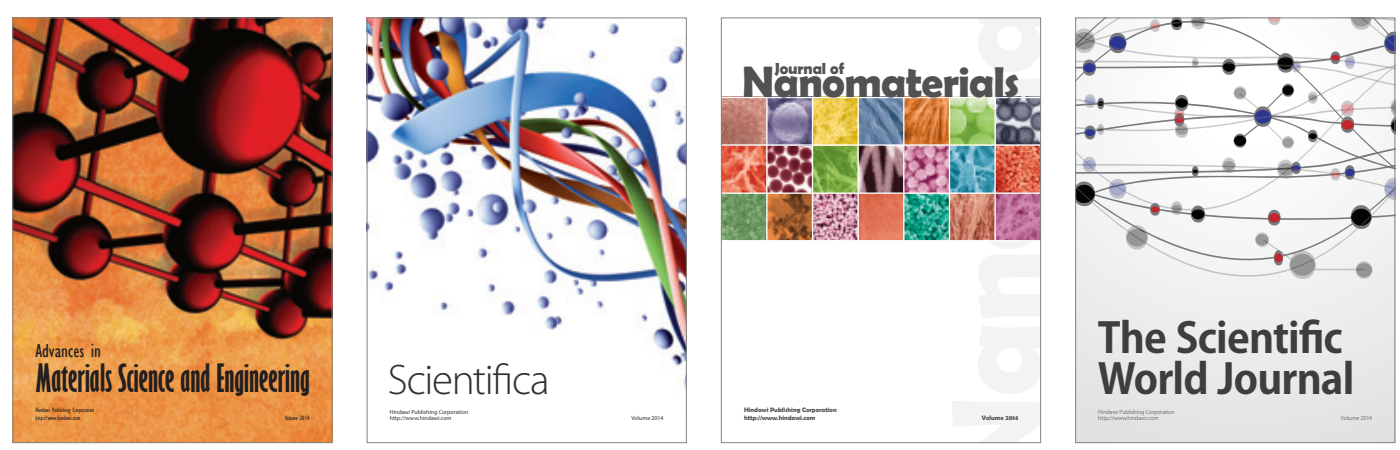

\section{The Scientific World Journal}
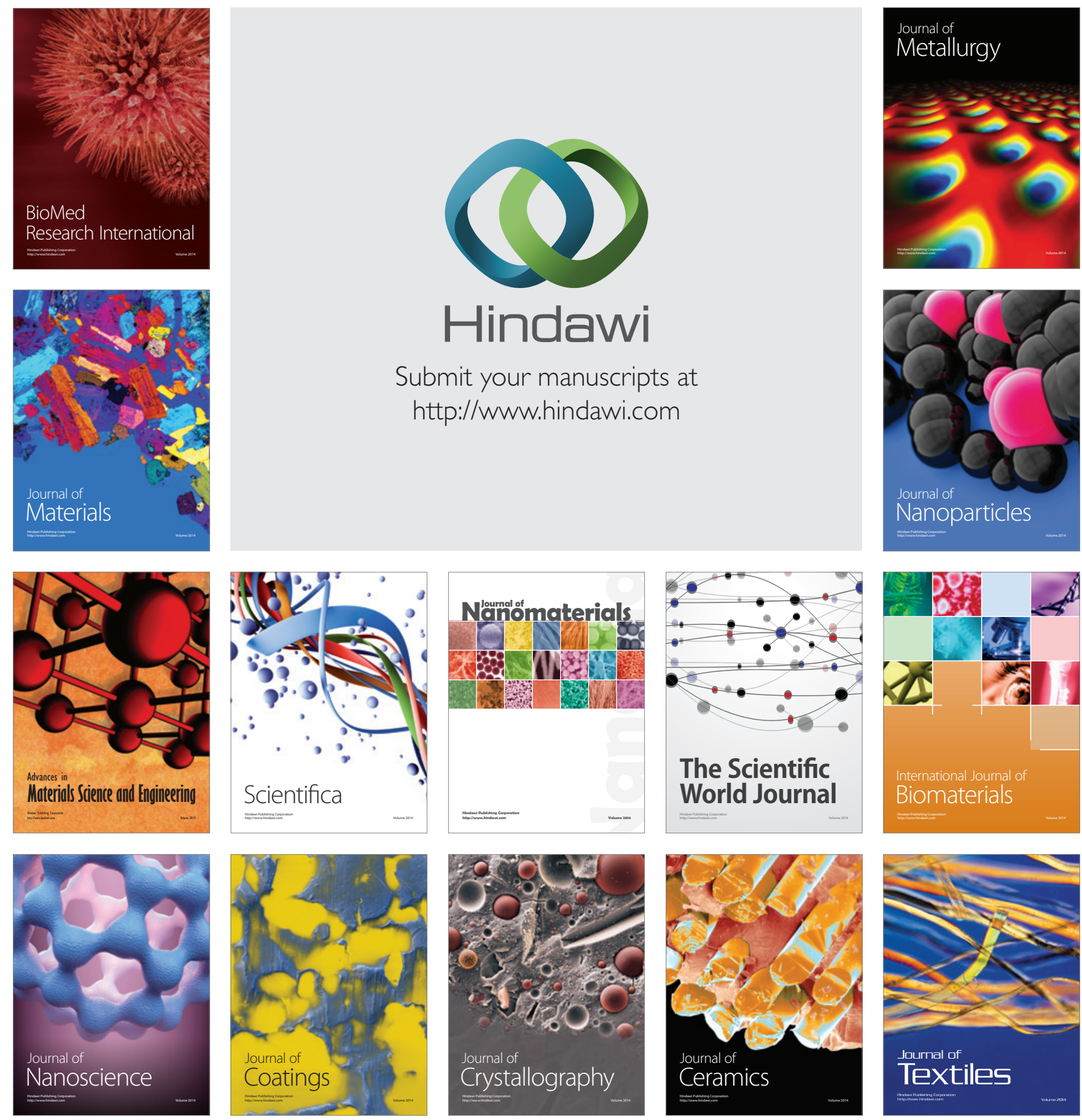